\title{
Quality of contraceptive services in Finland
}

\author{
E Hemminki, S Sihvo, P Koponen, E Kosunen
}

\begin{abstract}
Objective-To investigate whether the quality of contraceptive services in Finland varies by the type of care provider.

Design-A cross sectional questionnaire survey.

Participants-A random sample of 3000 Finnish women aged 18-44 years (response rate $74 \%$ ) in 1994 .

Results-Almost all women (94\%) had used contraception at some time and $\mathbf{7 5 \%}$ were current users. Although self care was common $(29 \%$ had obtained their latest method outside the health services), $83 \%$ had sometimes used the health services for contraception. For their last visit, 55\% of women had chosen a health centre (a publicly administered and funded health service), and $33 \%$ a private unit. In the health centre, the care provider was usually a general practitioner or a public health nurse, whereas in private care the providers were gynaecologists. Women who used private care were more likely to be from higher social classes and urban areas. After adjustment for a women's background, the two groups were similar for most indicators of the quality of care, but access to care and woman's experiences of treatment were better with private care.

Conclusions-In terms of availability and choices the current system of contraceptive services in Finland is adequate. It is not always an integral part of municipal primary health care, and many women prefer private care for gynaecological services; this may cause problems of comprehensiveness and equality of care. (Quality in Health Care 1997;6:62-68)
\end{abstract}

Keywords: contraception; quality of services; service providers

\section{Introduction}

In western countries the prevention of pregnancies-contraception-was outside official health care and in the realm of lay people and unofficial healthcare providers up to the second half of this century. ${ }^{1}$ Much effort was required to get contraception accepted as a part of the official health services. Even today in some countries provision and financing of contraceptive services are separate from other health services, and in most countries, many providers are involved.

From a personal health point of view, contraception is a crucial element of family planning relating to issues such as unplanned pregnancies, abortions, sexually transmitted diseases, and adverse effects of contraceptives. Social considerations of pregnancies and births have further emphasised the importance of contraception. Due to these factors and the many users of contraceptives, the question of availability and quality of contraceptive services are important. Quality includes technical quality, as defined by experts, acceptability, and other aspects of satisfaction as defined by the users of services.

In Finland, the 1972 Primary Health Care Act stipulated that every municipality must have a health centre which provides, among other things, family planning services. Public health nurses or midwifes and general practitioners give family planning services in all health centres. These services are organised in different ways in different municipalities. An earlier dominant pattern was to have distinct family planning clinics with specialised personnel, or to have family planning services organised within maternity health clinics and school health care. In the past few years, however, primary healthcare services have been reorganised along the lines of population responsibility. In this system, each general practitioner may also offer contraceptive services. As well as these public family planning services, private gynaecologists and voluntary non-profit making organisations provide contraceptive counselling, especially in urbanised areas. University students have a special healthcare organisation providing heavily subsidised services. Public health nurses and midwives are not allowed to prescribe contraceptive pills, or to set intrauterine devices (IUDs), but they have a lot of responsibility for counselling and follow up. For general practitioners, training in family planning after qualification is not mandatory, but many take short courses with instruction on insertion of IUDs.

This study investigates whether the quality of contraceptive services in Finland varies by the type of care provider and the type of services (private or public). Quality of services was measured in four areas: preventive measures taken in the past year, appropriateness of contraceptive method, availability and provision of the service, and women's knowledge about fertility and contraception. To provide background information, the use of contraception and the services in Finland are described.

\section{Methods}

THE SAMPLE

In 1994, a questionnaire was posted to a random sample of 3000 Finnish women aged 18-44 years; the names and addresses were 
obtained from the population register, which covers all residents. The population register is a continuously updated nationwide computerised register in which people are unequivocally identified by a personal identification number. After defining the years of birth and sex, a random sample was generated, a table of background characteristics created, and name tags provided for us.

Because the survey was multipurpose, no formal power calculations were made. The size of 3000 was the lowest calculated to provide enough young women and women with infertility problems (estimated lifetime incidence $15 \%$ ). Women younger than 18 were not included, because inclusion of minors would have complicated the survey procedure: the questionnaire would have had to be modified and possibly parental approval would have been needed.

\section{THE QUESTIONNAIRE}

The questionnaire covered various aspects of reproduction, including family planning, gynaecological check ups, abortions, pregnancies, and infertility, with a focus on use of and opinions about health services. Most questions were of the multiple choice type, in which the right or best option was to be circled, but some open questions as well as a few with scales were included. The box lists the main areas in which the questions on the quality of services were based. (The full questionnaire is available from the authors.)

\section{Women's survey}

AREAS IN WHICH QUESTIONS WERE BASED

Background information (Q1-7)

Health and healthcare (Q8-18)

Pregnancies and children (Q19-28)

Contraception (Q29-48)

Your last visit for contraception (Q49-55)

Miscarriages and abortions (Q56-58)

Prenatal care and labour (Q69-76)

Infertility (Q77-85)

Valuation of services (Q86-87)

Positive and negitive experiences (Q8889)

Basic education was assessed by questioning the type of school respondents had attended, and the responses were classified into three levels with high school being the highest class. Due to a national change in education policy, only older women could have the lowest education level. In a separate question advanced education was assessed. Occupation was assessed with an open question and coded according to the official Finnish classification. ${ }^{2}$ Three of these groups (upper white collar workers, lower white collar workers, and blue collar workers) also represent a social class gradient. Age was calculated from the year of birth. Women were asked whether they were currently pregnant and how many births, miscarriages, ectopic pregnancies, and induced abortions they had had, and with these data pregnancy and birth experiences were calculated. For health status, a global subjective estimate was used-how would you rate your current level of health?-with the option of, good, fairly good, average, fairly poor, and poor. Women who had used contraception at any time in the past are referred to as users (Q29) and women who were using contraception at the time of the survey are called current users.

\section{QUALITY INDICATORS}

Preventive measures

Preventive measures were studied by asking if certain examinations (PAP smear, gynaecological examination, breast palpation by a doctor or nurse, blood pressure measurement (Q18)), and visits to a public health nurse were made during the past year (Q40). In Finland, public health nurses and midwives are considered to be experts in counselling and health education.

Appropriateness of the contraceptive method Appropriateness was measured with the following indicators: proportions of women currently using unreliable methods (foam, cream, suppositories only, rhythm method, withdrawal (Q29)); male sterilisation (considered to be a positive option (Q29)); IUD for nulliparous women (Q29); answers to the question-how satisfied are you with your current method (Q31); estimated yearly contraceptive expenses of $500 \mathrm{Fmk}$ or more ( $£ 60$ or more) (Q34).

\section{Availability and provision of services}

The following indicators were used:

(1) The woman was a current contraceptive user, but had not visited a physician, public health nurse, or midwife because questions related to contraception during the past year (Q29, 49).

(2) The woman experienced some difficulty in visiting a physician during the past year (Q42).

(3) Costs hindered contraceptive use during the past year (either through choice of method, visiting a physician, or having laboratory tests) (Q35).

(4) Long waiting time to get an appointment for the last visit (Q52).

(5) The woman considered that her own opinion was ignored in selecting a contraceptive method during the past visit (Q53, 54).

(6) Satisfaction with the last contraceptive visit was assessed with a scaled question (Q55).

\section{Knowledge}

Knowledge was measured by asking multiple choice questions about the effect of a woman's age on her ability to get pregnant (Q27), the easiest point in the menstrual cycle to become pregnant (Q28), familiarity with three less commonly used contraceptive methods (capsules, diaphragm, 
Table 1 Use of healthcare services because of contraception and current use of different contraceptive methods* by age (\% of women)

\begin{tabular}{|c|c|c|c|c|c|c|c|}
\hline & \multicolumn{7}{|l|}{ Age (y) } \\
\hline & $18-19$ & $20-24$ & $25-29$ & $30-34$ & $35-39$ & $40-44$ & Totalt \\
\hline \multicolumn{8}{|l|}{ Healthcare services: } \\
\hline Number & 119 & 358 & 417 & 446 & 435 & 404 & 21899 \\
\hline Has used contraception & 73 & 89 & 96 & 97 & 97 & 96 & 94 \\
\hline Current user & 63 & 74 & 73 & 74 & 78 & 79 & 75 \\
\hline Has used healthcare services & 55 & 78 & 88 & 89 & 86 & 81 & 83 \\
\hline Used health care in past year & 45 & 59 & 54 & 41 & 42 & 28 & 46 \\
\hline Mean (SD) number of visits in past year (A) & $0.8(1.1)$ & $1.0(1.3)$ & $0.8(0.9)$ & $0.8(1.1)$ & $0.7(1.5)$ & $0.4(0.7)$ & $0.7(1.1)$ \\
\hline \multicolumn{8}{|l|}{ Mean (SD) number of all outpatient visits in past } \\
\hline year \| (B) & - & - & $2.6(3.7)$ & $2.6(3.4)$ & $2.9(7.0)$ & $2.7(5.1)$ & $2.7(5.1)$ \\
\hline $\mathrm{A} / \mathrm{B}(\%)$ & - & - & 31 & 31 & 24 & 15 & 26 \\
\hline \multicolumn{8}{|l|}{ Contraceptives: } \\
\hline Number & 88 & 318 & 399 & 434 & 420 & 388 & 2056 \\
\hline Pill & 60 & 63 & 45 & 23 & 14 & 4 & 29 \\
\hline Condom $\$$ & 25 & 15 & 23 & 21 & 19 & 17 & 20 \\
\hline \multicolumn{8}{|l|}{ IUD: } \\
\hline Usual $\ddagger$ & 0 & 2 & 4 & 14 & 25 & 21 & 13 \\
\hline Hormone & 0 & 0 & 2 & 9 & 8 & 7 & 5 \\
\hline \multicolumn{8}{|l|}{ Sterilisation: } \\
\hline Female & 0 & 0 & 0 & 4 & 11 & 26 & 8 \\
\hline Male & 0 & 0 & 0 & 1 & 2 & 3 & 1 \\
\hline Other & 0 & 2 & 2 & 3 & 1 & 2 & 2 \\
\hline Do not use now & 14 & 18 & 23 & 24 & 20 & 18 & 21 \\
\hline No information & 1 & 0 & 1 & 1 & 0 & 2 & 1 \\
\hline Total & 100 & 100 & 100 & 100 & 100 & 100 & 100 \\
\hline
\end{tabular}

‡ Includes women who have used contraception at some time.

† Includes women with age information lacking $(n=9)$.

$¥$ Includes those who used condoms.

Includes those who used chemical or natural methods.

II Includes women with age information lacking.

\| Source was unpublished data from a 1993 survey; for description see Aro et al. ${ }^{3}$

emergency contraception) (Q37), and grading of contraceptive methods by their effectiveness (Q38).

\section{ANALYSIS}

In cross tabulations significance of the differences was tested with the $\chi^{2}$ test. When the quality of services (with the indicators above) in private care and health centres were compared, the differences in women's background characteristics were adjusted for by logistic regression. The background characteristics were first entered in the model and then an odds ratio (OR) for each indicator of quality was calculated with "private" as the reference group. Age was entered as a continuous variable and for women with missing information the mean was used. Basic education (three groups), marital status (single, cohabiting, married, divorced, or widowed), type of residence (urban, semiurban, rural) and county ( 11 counties after combining Ahvenanmaa with Turku and Pori) were used as categorical variables, excluding women with missing information. For some rare events, ORs were not possible to calculate.

\section{Results}

After two reminders, 2189 (73\%) answered; excluding women who could not be reached or who, according to the response of a relative, were unable to answer, the response rate was $74 \%$. The respondents were relatively similar to the original sample for the studied background variables (age, marital status, locality, county), but the response rate declined somewhat with increasing age (from $77 \%$ to $66 \%$ by five-year age groups) and divorced women responded less often $(57 \%)$ than other women.
USE OF CONTRACEPTION

Three out of four women aged 18-44 were current users of contraception, and almost all women over 24 years had used it at some time (table 1). With the exception of the youngest age group, most had visited a health professional because of contraception. Compared with the total number of all outpatient visits (available from another representative survey $^{3}$ ) those for contraception represented a considerable proportion of all healthcare visits (table 1).

The most common methods currently used were contraceptive pills $(30 \%$ of the 2056 users), condoms (20\%), IUDs (13\% usual and $5 \%$ hormone IUD), and sterilisation ( $9 \%$ ); $20 \%$ were past users and were currently using no contraception. As expected, there was a notable variation in methods used by women's age, with pills being much more common among younger women, and IUDs and sterilisation more common among older women; condoms were commonly used in all age groups (table 1).

\section{SELF CARE $V$ PROFESSIONAL CARE}

Of contraceptive users, $14 \%$ had acquired their latest contraceptive method outside health care. When the women whose partners had acquired the contraceptive (mostly condoms bought outside health care) were included, almost a third of the women had used self care (table 2). Judged from the contraceptive method used (condom, foam, cream, suppositories, rhythm method, or withdrawal), it is estimated that $84 \%$ of women have sometimes relied on self care in contraception.

The proportions of self care users did not notably vary by age, but were smallest among 20-24 year olds (table 2). Neither were there 
Table 2 Source of last contraceptive method, by age (\% of women $\left.{ }^{\star}\right)$

\begin{tabular}{llllllll}
\hline & \multicolumn{7}{l}{ Age $(y)$} \\
\cline { 2 - 7 } & $18-19$ & $20-24$ & $25-29$ & $30-34$ & $35-39$ & $40-44$ & Totalt \\
\hline Number & 88 & 318 & 399 & 424 & 420 & 388 & 2056 \\
Self care & 29 & 22 & 33 & 31 & 31 & 28 & 29 \\
(partner) & $(18)$ & $(11)$ & $(17)$ & $(16)$ & $(16)$ & $(16)$ & $(15)$ \\
Health service & 65 & 75 & 65 & 63 & 60 & 55 & 64 \\
Other & 6 & 3 & 2 & 6 & 9 & 17 & 7 \\
Total & 100 & 100 & 100 & 100 & 100 & 100 & 100 \\
\hline
\end{tabular}

ऋ Women who have used contraception at some time.

$\dagger$ Includes women with age information lacking $(n=9)$.

‡ Other, do not remember, no information.

Table 3 Last contraceptive visit by care provider and care site (\% of women *)

\begin{tabular}{lllll}
\hline & Private & Public & OtherS & Totalt \\
\hline Number & 604 & 998 & 209 & 1832 \\
Gynaecologist & 96 & 28 & 50 & 54 \\
General practitioner $\neq$ & 3 & 46 & 34 & 30 \\
Public health nurse & 0 & 22 & 12 & 13 \\
Other, no information & 1 & 4 & 4 & 3 \\
Total & 100 & 100 & 100 & 100 \\
\hline
\end{tabular}

ऋ Women who used health care at some time for contraception $(\mathrm{n}=1832)$.

$\dagger$ Includes women with no information on care site $(n=21)$.

¥ May also include public health nurse.

\Student or occupational health care.

notable differences in the use of self care by other background characteristics studied (education, marital status, having had children or not, locality of residence). Women from higher occupational groups (33\% of upper white collar workers) had more often used self care than workers $(23 \%, P<0.01)$, and there was a variation in the proportion of self care by county (from $20 \%$ to $42 \%, P<0.01$ ). The more frequent the need for contraception, the less the use of self care: $21 \%$ of those reporting a weekly need for contraception had used self care compared with $62 \%$ of those needing contraception a couple of times a year.

\section{PROFESSIONAL CARE}

The place of the last visit was assessed by giving ready alternatives and afterwards classifying responses into private and public (publicly administered and funded-such as family planning clinic, (other) municipal health centre, school health care, or hospital). The last visit of over half of the women (55\%) was made to a public unit. The most common place was a family planning clinic, which $35 \%$ of women had visited. One third of the women (33\%) had visited a private unit, and the rest of the women visited units difficult to classify into public or private.

The care provider for the last visit was assessed by giving ready alternatives; in the analysis "general practitioner" and "other physician" responses were combined and called general practitioners. In the private sector, practically all visits had been to a gynaecologist (table 3). In the public sector, the care provider indicated most often was a general practitioner or a public health nurse. A public health nurse was the sole care provider in $22 \%$ of visits, and an additional care provider in $49 \%$ of the visits in the public sector. Twenty eight per cent of the women having visited a public sector unit said they had seen a gynaecologist on their last visit. Taking into account the personnel structure of municipal health care (where few gynaecologists are employed), the answers show that women were not always aware or made aware of the qualifications of their health providers.

\section{QUALITY OF SERVICES}

Formation of comparison groups

To study the quality of services, women who had accessed health care for contraception in the past five years were first classified into four groups according to the services they had used for their last visit (Q49-51): private care $(n=515)$, municipal health centres including family planning clinics $(n=559)$, other health centre services $(n=228)$, and other service units $(n=271)$. Comparison of the background characteristics of the women and the quality indicators in the two health centre groups showed them to be very similar. Thus, to simplify presentation the two health centre groups were combined. The other group turned out to be a heterogenous group representing mainly women visiting student healthcare services and hospital clinics, and was excluded in the analysis of the quality of services.

Women who had visited private units and those who had visited health centres in the past five years were different. Users of private care were older, from higher social classes measured either by education or current occupation, and more often lived in urban areas and in the most southern county including the capital area (Uusimaa) (table 4). The differences in marital status, having had children or having been pregnant or not, and subjective estimate of current health were minor. The reason for the last contraceptive visit was similar in the two groups: for $57 \%$ it had been a follow up visit and for $25 \%$ to start contraception or change the method.

\section{Preventive measures}

More women in the private group had breast and gynaecological examinations during the past year than health centre users, but this was not true for PAP tests or blood pressure tests (table 5). Women in the health centre group had more often visited a public health nurse for contraception. Adjusting for background characteristics did not change these differences.

Table 4 Women's background characteristics by last care site $^{\star}$ (\% of women)

\begin{tabular}{lll}
\hline & Privatef & Health centre \\
\hline Number & 515 & 787 \\
Age (y): & & \\
$\quad<25$ & 10 & 27 \\
$\geq 35$ & 44 & 31 \\
Education: & & \\
$\quad$ High school (basic) & 59 & 41 \\
$\quad$ Polytechnic (further) & 4 & 27 \\
$\quad$ University (higher) & 18 & 8 \\
Upper white collar worker & 21 & 9 \\
Married & 53 & 46 \\
Births & 58 & 60 \\
Induced abortions & 16 & 12 \\
Urban residence & 71 & 56 \\
Uusimaa county & 36 & 20 \\
Current good health & 64 & 59
\end{tabular}

ऋ Only women visiting in the past five years are included. † Mostly gynaecologists.

$\ddagger$ A general practitioner or public health nurse. 
Table 5 Women who had preventive tests in the past year by last care site (\% of women and ORs (95\% CIs) adjusted for women's background characteristics) *

\begin{tabular}{|c|c|c|c|}
\hline & Privatet & Health centre‡ & OR $(95 \% C I)$ \\
\hline Number & 515 & 787 & - \\
\hline PAP smear & 67 & 70 & $1.07(0.82$ to 1.38$)$ \\
\hline Gynaecological examination & 86 & 76 & $0.47(0.34$ to 0.65$)$ \\
\hline Breast examination & 56 & 33 & $0.41(0.32$ to 0.52$)$ \\
\hline Blood pressure & 80 & 84 & $1.05(0.76$ to 1.44$)$ \\
\hline Visited a public health nurse last yearf & 3 & 37 & $15.4(8.57$ to 27.6$)$ \\
\hline
\end{tabular}

Table 6 Appropriateness of the contraceptive method by the last care site (\% of women and ORs (95\% CIs) adjusted for women's background characteristics)*

\begin{tabular}{|c|c|c|c|}
\hline & Privatef & Health centref & OR $(95 \% C I)$ \\
\hline Number & 437 & 690 & - \\
\hline Unreliable method & 0.9 & 1.3 & $1.61(0.44$ to 5.93$)$ \\
\hline IUD for nulliparous women $\S$ & 3.7 & $0.9 \star \star$ & - \\
\hline Male sterilisation & 0.5 & 1.2 & - \\
\hline Dissatisfied with the current method & 5.7 & 6.7 & $0.98(0.56$ to 1.69$)$ \\
\hline Yearly expenses high & 39.6 & 9.9 & $0.35(0.26$ to 0.46$)$ \\
\hline \multicolumn{4}{|c|}{$\begin{array}{l}\star \text { Age, basic education, marital status, urbanism, county; compared with private }(=1) \text {. Only } \\
\text { women currently using contraception. } \\
\text { † Mostly gynaecologists. } \\
\ddagger \text { A general practitioner or a public health nurse. } \\
\text { § Numbers of women: private } n=216 \text {; health care } n=316 \text {. } \\
\star \star P<0.01 \text {. }\end{array}$} \\
\hline
\end{tabular}

Table 7 Availability and provision of services by last care site (\% of women and ORs (95\% CIs) adjusted for women's background characteristics) *

\begin{tabular}{|c|c|c|c|}
\hline & Privatef & Health centref & OR $(95 \% C I)$ \\
\hline Number & 515 & 778 & - \\
\hline Current user with no visits in past year $\$$ & 44 & 36 & 0.79 (0.60 to 1.05$)$ \\
\hline Costs hindered contraceptive use & 7 & 7 & $1.08(0.66$ to 1.76$)$ \\
\hline Difficulties in visiting a physician & 17 & 24 & $1.33(0.93$ to 1.91$)$ \\
\hline Waiting time for appointment $\|$ : & 6 & & \\
\hline$\geq 21$ days & & 10 & $2.39(1.49$ to 3.83$)$ \\
\hline$<7$ days & 42 & 30 & $0.51(0.39$ to 0.66$)$ \\
\hline Own opinion ignored $\| \star \star$ & 7 & 10 & 1.45 (0.84 to 2.52$)$ \\
\hline \multicolumn{4}{|l|}{ Very satisfied with II: } \\
\hline Friendliness & 73 & 57 & $0.50(0.39$ to 0.65$)$ \\
\hline Competence & 81 & 51 & $0.23(0.17$ to 0.30$)$ \\
\hline Confidentiality & 85 & 66 & $0.32(0.24$ to 0.44$)$ \\
\hline Adequacy of time & 67 & 59 & $0.73(0.57$ to 0.94$)$ \\
\hline
\end{tabular}

* Age, basic education, marital status, urbanism, county; compared with private $(=1)$

† Mostly gynaecologists.

$\mp$ A general practitioner or a public health nurse.

Only current contraceptive users: private $n=429$; health centre $n=681$.

If Only women wanting to visit a physician for contraception in the past year: private $n=361$; health centre $n=577$.

II Last visit.

$\star \star$ In selection of contraceptive method; only women whose last visit was for that purpose: private $n=342$; health centre $n=485$.

Appropriateness of the contraceptive method The distribution of contraceptive methods used was very similar for the two groups, and the prevalence of special indicators was low in all groups (table 6). But use of IUDs for nulliparous women was more common among women who used private care. There was no difference in satisfaction with the current contraceptive method (48\% v 53\%) (table 5). In the private group there were notably more women with high expenses $(\geq 500 \mathrm{Fmk}=£ 60)$.

\section{Service availability and provision}

There was no difference between the groups in the proportion of current contraceptive users who had not visited healthcare centres because of costs of services or contraceptives in the past year (table 7). More health centre users had experienced some difficulty in getting access to a physician. The difference was mainly due to difficulties in getting an appointment time
(4.7\% of private care users and $9.0 \%$ of health centre users). This was reflected also in waiting times; health centre users more often had to wait longer before getting an appointment (table 7). Other problems were rare and relatively evenly distributed between the groups.

In both groups, women's own opinions were rarely ignored when the contraceptive method was chosen. The women in the private group were more satisfied with the way they had been treated in their last visit than the women in the health centre group. Adjustments for women's background characteristics did not change these differences (table 7).

\section{Knowledge}

By the indicators used, the levels of knowledge of the two groups studied were similar.

\section{Discussion}

This nationwide survey showed that contraception concerns most women of childbearing age: almost all had used contraception at some time, and $75 \%$ were using it at the time of the survey. Two thirds had obtained their latest contraceptive method from health services, but self care was also common in all age groups. Visits for contraception represented a notable proportion of all healthcare visits. By the chosen indicators, the quality of service was good and very similar in the two provider groups studied. The potential problems are likely to be due to organisational effects - such as difficulties in getting appointments-rather than individual encounters.

In many health related problems patients have difficulties in making independent care choices because they do not have the necessary information. ${ }^{45}$ In contraception, most women know their needs well, and in countries such as Finland where there is ample sex education, women are also familiar with the contraceptive methods available. Thus most Finnish women are capable of making informed choices about contraception. Since the early 1970 s municipalities have been required to provide public contraceptive services, but unlike for example, prenatal care and well baby clinics, ${ }^{6}$ no uniform service system has developed. This survey showed that, as well as self care, women use a wide variety of public services and to a great extent also private services. In private services the care provider is almost always a gynaecologist, and in public services most commonly a general practitioner or a public health nurse.

The type of service used varied by population groups: urban and older women and women from higher social classes more often visited specialists in private care. This difference can probably be explained in part by provision of the service. Rural women have less private care available to them. Access to public services may be more difficult in urban areas. Whether these differences by age are real (older women having more need, willingness, or money to consult a specialist), or a cohort effect (more recent cohorts are more apt to use 
public services) cannot be studied in this cross sectional survey. If it is a cohort effect we may expect more use of public services in the future.

Medical expertise needed for contraceptive services depends on a woman's health and the type of contraceptive method chosen. With the exception of sterilisations and sick women with special needs, we think that contraception is in the realm of primary health care. Such services are available in health centres in all Finnish towns. Why did women then use specialist care? Women were more satisfied with the care they had received from specialists than in health centres, and as reported elsewhere, women prefer a gynaecologist over a general practitioner in providing contraception (E Hemminki et al, unpublished data). The other measures of quality of care did not systematically suggest that the content of specialist care was better than care in the health centre. Some tests were more usual in those women who had relied on a specialist, but they had less often met a public health nurse who, in Finland, can be considered the specialist in health education. Use of inappropriate contraceptive methods was low in both groups. Access to specialist care was easier, but the costs were higher. Women's knowledge on contraception was similar. Our results suggest that in a medical sense the quality of care was similar in the health centre and in specialist care, but access to care and women's experiences of their treatment was poorer in the health centre.

However, to study medical quality thoroughly, a different study design-for example, studying providers themselveswould be needed. Also the chosen indicators of the quality of care can be challenged. (This study was based on a multipurpose survey, and for each aspect only a few questions could be asked. Thus, to have a broader picture as well as the questions originally designed to measure the quality of services, we used other questions.) For example, in the Finnish practice, the use of IUDs for women not having given birth is not usually considered appropriate. Use of male sterilisations in the country with a high female/male sterilisation ratio (E Hemminki, unpublished data) can be considered an indicator of many options. But the validity of both of these indicators can be questioned. Likewise, some may not consider gynaecological or breast examinations as indicators of good care, but rather as competitors for time better used in counselling. Knowledge of fertility and contraception is likely to measure information given outside the services studied. But it could also be argued that good services should provide further information and that deficiencies indicate failure of the services. We do not claim that the indicators used are the best, and certainly they do not cover all aspects considered important in good quality contraceptive services. However, we think that for comparative purposes they are suitable.

Different women had visited specialists and health centres, and hence the women could not compare their experiences of both. We adjusted for differences in some background characteristics, but cannot be sure that all relevant ones-for example, differences in expectations and attitudes, were accounted for. For example, in Finland visiting a specialist means getting private care. It is possible that some of the differences were due to the different images and expectations of public and private care, private care having higher prestige. Also because women in private care pay for themselves, they may be more assertive and open in their expectations and in that way receive better care. Or, perhaps the higher ratings were a retroactive justification for having paid.

It would have been interesting to compare the results on the quality of services of different care providers with results from other studies. We did not find any similar studies, but sporadic data on specific aspects suggested similar findings. A study from the United States based on care providers showed that gynaecological and breast examinations were more commonly done by gynaecologists than by general practitioners. ${ }^{8}$ In that study PAP smears were also more often performed by gynaecologists. A study from England comparing women treated for menorrhagia by public (National Health Service) and private specialists showed that although the therapeutic decisions made were similar, women attending private clinics more often reported active participation in decision making and they were more satisfied with the care they received. ${ }^{9}$ In this study both groups of providers were gynaecological specialists, making it more likely that the differences were due to different styles of dealing with patients in the private and public sectors. In a previous Finnish study, women having received their IUD from a gynaecologist did not know more about side effects than women who had received it from a general practitioner. ${ }^{10}$

Do the results of this study suggest that changes should be made to the current method of providing contraceptive services in Finland? If availability and choices are used as criteria, the current system seems to work well: there are many different providers, only few women complained of the problems of access or costs, and most women were satisfied with the services they had received. Many relied on self care, and there was little pressure to get more types of contraceptives on a free prescription (E Hemminki et al, unpublished data). If equality, uniformity, comprehensiveness, integration with other personal health services, and overall costs are emphasised ${ }^{11}$ health centres should have a more prominent place in contraception. Our study does not suggest that the medical content of specialist care was any better. Either the public image of contraceptive services or their organisation within the health centres should be critically studied to provide better access and customer satisfaction. Broader information about the existence of municipal services could raise expectations and demands, and increase pressure for more, or more efficient and better quality contraceptive services. 
1 McLaren A. A history of contraception. From antiquity to the present day. Oxford: Basil Blackwell, 1990.

Statistics Finland. Sosioekonomisen aseman luokitus 1989. Käsikirioja 17. Helsinki: Statistics Finland, 1989.

3 Aro S, Byckling T, Häkkinen U, Kerppilä S, Salonen M Aikuisväestön terveyspalveluiden käyttö ja terveydentila 1993. Aiheita 24/1994. Helsinki: Stakes, 1994

4 Higgins J, Wiles R. Study of patients who choose private health care for treatment. Br f Gen Pract 1992:42:326-9.

5 Cant SL, Calnan M. Using private health insurance. A study of lay decisions to seek professional medical help. Sociology Health Illness 1992:14:39-56.

6 Hemminki E, Malin M, Kojo-Austin H. Finnish prenatal care: from primary to tertiary health care. Int $\mathcal{f}$ Health Services 1990:20:221-32.
7 Robey B, Piotrow PT, Salter C. Making programs work. Baltimore: Population Information Program, The Johns Hop-
kins School of Public Health, 1994. (Population reports, series 1,40 .)

8 Bartman BA, Weiss KB. Women's primary care in the United States: a study of practice variation among physician specialties. 7 Women Health 1993:2:261-8.

9 Coulter A, Peto V, Doll H. Gynaecology: the experience of patients referral to NHS and private clinics. Health Trends 1995:27:57-61.

10 Makkonen K, Hemminki E, Uutela A. Is users' knowledge about contraceptives adequate? A case study of Finnish IUD users. Soc Sci Med 1992:35:1131-6.

11 Starfield B. Primary care. Concept, evaluation, and policy. New York: Oxford University Press, 1992.

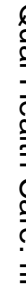

